\title{
„Czy dotyka cię czas?”. Foto-grafemiczność tekstu na podstawie utworu Tomasza Różyckiego Las tropikalny*
}

\author{
* Praca powstała w wyniku \\ realizacji projektu badawczego \\ o $\mathrm{nr}$ 2018/31/N/HS2/02651 \\ finansowanego ze środków \\ Narodowego Centrum Nauki.
}

\section{Barbara Englender}

ORCID: 0000-0002-4107-0801

W tomiku Kolonie Tomasza Różyckiego odnaleźć można następujący wiersz:

Kiedy dla mnie zatańczysz? Skończyło się lato, wielkie desanty dmuchawców, zielona fabryka, wchodząca nam do łóżka, brudząca nam życiem pościel, ubrania, palce. Było tak bogato

i dzieci nam urosły, i wojnę ze światem prowadziliśmy znowu, tak, jak to wynika ze zdjęć, będąc po stronie świata. Czy dotyka cię czas? Ze zdjęcia na zdjęcie, czy przypadkiem

nie znika jakiś drobny szczegół? I czy w końcu tylko już tło zostanie? Robione pod słońce fotografie $z$ wesela. Poprawiny były i jutro będą znowu, chociaż puste wszystkie butelki ze złym winem i na dnie kieliszka zawsze coś pozostaje, jakieś fusy, miłość ${ }^{1}$

\footnotetext{
${ }^{1}$ Tomasz Różycki, „Las tropikalny”, w Kolonie (Kraków: Wydawnictwo Znak, 2007), 66.
} 
Magdalena Rabizo-Birek w tekście Poezja bliska, stanowiącym wstęp do książki Obroty liter. Szkice o twórczości Tomasza Różyckiego, w następujący sposób osadzała twórczość tego autora w kontekście polskiej tradycji literackiej:

Różycki określany był przez krytyków metaforycznymi quasi-terminami: „o’harystyczny klasycysta” (Karol Maliszewski), „romantyczny klasycysta” (Magdalena Rabizo-Birek), ale też uznawano go za czołowego przedstawiciela „szkoły obrazu”, „poezji wizji”, nurtu „ośmielonej wyobraźni” w poezji roczników siedemdziesiątych (Marian Stala, Jakub Momro, Karol Maliszewski)².

W kręgu tematów poruszanych przez Różyckiego niezwykle istotne miejsce zajmuje problem Kresów, bezpośrednio związany z losami jego rodziny, przesiedlonej z okolic Lwowa do Opola. W poetyce tego autora doświadczenie tęsknoty i braku splata się z - jak to określała, za chociażby Edwardem W. Saidem, Magdalena Piotrowska-Grot - gestem „«tworzenia światów możliwych»"3 a także świadomością, że w naszej dyspozycji pozostają często jedynie - by tym razem posłużyć się sformułowaniem samego poety - „fałszywe mapy”. Ich dekodowanie daje dostęp do innej przestrzeni: onirycznej, ale i napiętnowanej poczuciem samotności czy utraty.

Dla poetyki Różyckiego charakterystyczna jest również niezwykle przemyślana (by nie rzec: kunsztowna) budowa tomików. Świetnym przykładem może być książka Kolonie, z której pochodzi cytowany wiersz - tomik, składający się z 77 sonetów francuskich, na przestrzeni którego niemal refrenicznie pojawia się fraza „Kiedy zaczynałem pisać, nie wiedziałem jeszcze”. Jej rozwinięcia - jak podkreśla Justyna Tabaszewska - stanowią „próbę odpowiedzi [...] świadomie nieostateczną, niekonkluzywną"5.

Magdalena Drzęźla w tekście dotyczącym problemów w translacji podkreślała, że cały ten zbiór w pewien sposób podporządkowany jest kategorii obcości - uwidaczniającej się chociażby w tytułach poszczególnych wierszy ${ }^{6}$. Nie inaczej jest w przypadku przytaczanego Lasu tropikalnego, którego tytulatura w oczywisty sposób przywołuje konteksty podróżnicze ${ }^{7}$. Jednocześnie jednak problem obcości w Lesie tropikalnym wykracza daleko poza proste relacje geograficzne, sięgając samego sedna ludzkiej tożsamości. Zawiera się on w doświadczeniu upływu czasu, przemian zachodzących w związku z dorastaniem czy starzeniem, a także w świadomości własnej śmiertelności. Wszystkie te problemy uwidaczniane są w konfrontacji $\mathrm{z}$ dawnymi zdjęciami.

${ }^{2}$ Magdalena Rabizo-Birek, „Poezja bliska”, w Obroty liter: Szkice o twórczości Tomasza Różyckiego, red. Anna Czabanowska-Wróbel i Magdalena Rabizo-Birek (Kraków: Towarzystwo Autorów i Wydawców Prac Naukowych UNIVERSITAS, 2019), 12.

${ }^{3}$ Magdalena Piotrowska-Grot, „Po kolei wszystkie warianty”, w Obroty liter: Szkice o twórczości Tomasza Różyckiego, red. Anna Czabanowska-Wróbel i Magdalena Rabizo-Birek (Kraków: Towarzystwo Autorów i Wydawców Prac Naukowych UNIVERSITAS, 2019), 119.

${ }^{4}$ Co znamienne, utworów ją wykorzystujących jest również siedem.

${ }^{5}$ Justyna Tabaszewska, „Powtórzenia i ponowienia,/. Tomasz Różycki a kwestia oryginalności”, w Obroty liter: Szkice o twórczości Tomasza Różyckiego, red. Anna Czabanowska-Wróbel i Magdalena Rabizo-Birek (Kraków: Towarzystwo Autorów i Wydawców Prac Naukowych UNIVERSITAS, 2019), 171.

${ }^{6}$ Magdalena Drzęźla, „O problemach tłumaczenia”, Kwartalnik Opolski : organ Opolskiego Towarzystwa Przyjaciót Nauk., nr 4 (2010): 154.

${ }^{7}$ Mira Rosenthal, „Teraźniejszość jako niekończąca się chwila wahania”, w Obroty liter: Szkice o twórczości Tomasza Różyckiego, red. Anna Czabanowska-Wróbel i Magdalena Rabizo-Birek, tłum. Tomasz Bilczewski i Anna Kowalcze-Pawlik (Kraków: Towarzystwo Autorów i Wydawców Prac Naukowych UNIVERSITAS, 2019), 277-84. 
Sposób, w jaki Różycki wprowadza do swego utworu motyw fotografii, wydaje się szczególnie interesujący. Ani tytuł tekstu, ani też jego pierwsza strofa - mimo pewnej „obrazowości”, na którą jako cechę chrakaterystyczną tej poezji, za przytaczanymi krytykami, wskazuje Magdalena Rabizo-Birek - nie zdają się sugerować takiej tematyki, choć to na niej opiera się w dużej mierze wymowa całego tekstu. Fotografia pojawia się dopiero w połowie drugiej strofy, a moment wprowadzenia tego medium zbiega się z przekształceniem optyki, stosowanej przez Różyckiego w pierwszej części sonetu.

Edward Balcerzan w badaniach nad wizualnością tekstu literackiego posługiwał się pojęciem „wizualizmu”, stworzonym - jak sam podkreślał - „per analogiam do takich językoznawczych terminów, jak wulgaryzmy, poetyzmy, technicyzmy, etc”. Termin ten miał obejmować „wyrazy i wyrażenia z poziomu leksykalno-frazeologicznego - należące do językowej reprezentacji wzrokowych doświadczeń człowieka"9. Podążając podobną drogą, proponuję wykorzystanie pojęcia „foto-grafemiczności” (rozumianej jako zespół cech wskazujących na pokrewieństwo tekstu i fotografii) oraz "foto-grafemu” (będącego ich jednostkową tekstową realizacją). O ile „foto-grafemiczność" byłaby określeniem dotyczącym całego utworu (bądź pewnych jego partii), o tyle „foto-grafem” stanowiłby podstawowy element, w jakim przejawia się splot łączący tekst z fotografią. Jeśli trzymać się wskazanego przez Adama Dziadka chiazmu jako figury unaoczniającej relacje między sztukami wizualnymi a literaturą ${ }^{10}$, to „foto-grafem” byłby znajdującym się w jego sercu węzłem; miejscem centralnym, wyznaczającym swoisty „punkt styku" pomiędzy tymi dwoma mediami.

Obydwa proponowane terminy („foto-grafemiczność” i „foto-grafem”) w wyraźny sposób inspirowane są Derridiańskimi kategoriami "gramatologicznymi”. W kreowaniu tych pojęć w oczywisty sposób niezwykle istotna jest definicja grafemu stworzona przez Jacques’a Derridę:

Gram [gramme] lub grafem - zanim nawet określony zostanie jako ludzki [...] lub jako nie-ludzki - określałby w ten sposób element podstawowy. Element nieprosty. Rozumiany jako ośrodek lub nieredukowalny atom, element pra-syntezy w ogóle, element tego, czego nie powinniśmy definiować wewnątrz systemu opozycji metafizyki, tego więc, czego w ogóle nie należałoby nazywać doświadczeniem w ogóle, ani też źródłem sensu w ogóle ${ }^{11}$.

Odwołanie do myśli twórcy Farmakonu pozwala wyakcentować „piśmienność” fotograficznej rejestracji obrazu, zanurzenie jej w przestrzeni znakowej. Gramatologia Derridy decentralizuje wszakże „fonocentryczny” model języka, kierując uwagę w stronę widzialnych, materialnych śladów pisma.

\footnotetext{
${ }^{8}$ Edward Balcerzan, „Widzialne i niewidzialne w sztuce słowa”, w Kulturowe wizualizacje doświadczenia, red. Włodzimierz Bolecki i Adam Dziadek (Warszawa: Instytut badań literackich : Fundacja „Centrum międzynarodowych badań polonistycznych, 2010), 489.

${ }^{9}$ Tamże.

${ }^{10}$ Por. Adam Dziadek, Obrazy i wiersze: z zagadnień interferencji sztuk w polskiej poezji wspótczesnej (Katowice: Wyd. Uniwersytetu Śląskiego, 2011), 16.

${ }^{11}$ Jacques Derrida, O gramatologii, tłum. Bogdan Banasiak (Łódź: Wydawnictwo Officyna, 2011), 33.
} 
W podobny sposób - choć na zupełnie innej płaszczyźnie pojęciowej - z kategorii wypracowanych przez Derridę korzystał Lee Edelman w tekście Homographesis. Cytując artykuł Marie-Rose Logan, Edelman zauważał:

[...] Logan definiuje graphesis jako „punkt węzłowy artykulacji tekstu”, który „za-kreśla [de-limits] miejsce, w którym podnosi się kwestię pisma” oraz „za-pisuje [de-scribes] czynność pisania w momencie, w którym aktualizuje się ono w tekście, niezależnie od pojęcia intencji” ${ }^{12}$. Wychodząc od Derridy i jego post-saussurowskiej charakterystyki pisma jako systemu différance działającego bez pozytywnych warunków i nieustannie odraczającego osiągnięcie tożsamości rozumianej jako samoobecność, możemy powiedzieć, że graphesis - wejście w pismo, której doprecyzowaniem ma nadzieję być homographesis - nie jest wyłącznie tym, za sprawą czego „homoseksualna tożsamością” jest przez heteroseksualną kulturę rozmaicie konceptualizowaną jako coś czytelnie zapisane na ciele, ale jest także tym, w czym, poprzez sprowadzenie do pozycji pisma w tradycji zachodniej metafizyki, decyduje się sens samej „homoseksualnej tożsamości” ${ }^{{ }^{13}}$.

W przypadku fotograficznego graphesis interesuje mnie najsilniej kwestia „za-pisania” [de-scribes], stanowiącego nieodłączny element rejestracji obrazu. Walor ten zakodowany jest już w źródłosłowie określenia tego medium, stworzonym przez Johna Herschela (photo - związane ze światłem, graphie - pismo). Pozwala również podkreślić wspólny „rodowód” pisma i fotograficznego obrazu, a także wykazać paralele pomiędzy tymi sposobami rejestracji - również w kontekście zmian związanych z postępem technicznym.

Lee Edelman w następujący sposób ujmował relacje między pojęciem pisma a aktem pisania (czerpiąc, rzecz jasna, z Derridiańskiego ujęcia):

„pismo”, zwłaszcza w formie rzeczownika odczasownikowego („pisanie”) zbliżającej nas do sensu słowa graphesis, służy do wyrażania tożsamości tylko w relacji do znaków ustrukturyzowanych jak ujmuje to Derrida - przez ich „nie-tożsamość ze sobą”. Chociaż oznacza i opisuje różnice, na których zasadza się specyfika tożsamości, pismo w tym samym momencie działa, by (jak ujmuje to Logan) „za-pisać” [de-scribe], wymazać, odczynić tożsamość poprzez wkomponowanie różnicy w ramy nie(do)rozpoznanej [misrecognition] différance, której negatywność i czysto relacyjna artykulacja kwestionują możliwość jakiejkolwiek pozytywnej obecności lub odrębnej tożsamości. Homographesis, niczym pismo, nazywałoby zatem podwójne działanie: $\mathrm{z}$ jednej strony służba ideologicznym celom konserwatywnego porządku społecznego, skupienie na kodyfikacji tożsamości w pracy na rzecz dyscyplinującej inskrypcji, z drugiej strony - opór wobec tych kategoryzacji, skupiony na za-pisywaniu tożsamości, które konserwatywny porządek tak opresyjnie wpisał ${ }^{14}$.

Choć w przypadku fotografii na pierwszy plan w naturalny sposób wysuwa się problem zapisu (rozumianego często jako mechaniczna rejestracja), to jednak transpozycja tego medium w przestrzeń najnowszej polskiej poezji również niesie w sobie walor tożsamościowy - zwłaszcza jeśli rozważyć wspólnotowy aspekt doświadczenia przełomu cyfrowego. Jak podkreślała Catherina

\footnotetext{
${ }^{12}$ Marie-Rose Logan, „Graphesis...”, Yale French Studies Yale French Studies 52, nr 4 (1975): 12, cyt. za .Lee Edelman, „Homographesis”, w Formy męskości 3, red. Adam Dziadek i Filip Mazurkiewicz, tłum. Dawid Matuszek, Instytut Badań Literackich PAN (Warszawa, 2018), 322.

${ }^{13}$ Tamże.

${ }^{14}$ Tamże.
} 
Malabou, „[z]godnie z [...] ontologią grafu, źródło [...] daje się pomyśleć tylko w kategoriach śladu, to znaczy własnej wewnętrznej różnicy" ${ }^{15}$ - z jego prymarnością nad formą ${ }^{16}$. W ciekawy sposób w pojęciu foto-grafemiczności wybrzmiewa także aspekt cielesności - wszakże „maszyny widzenia” (jak chciałby Paulo Virilio) stanowią jedynie przedłużenie ludzkiego oka czy ręki.

Proponowane przeze mnie pojęcia mają na celu ułatwienie określenia wszelkiego rodzaju związków - tak semantycznych, jak i formalnych czy stylistycznych - łączących sposób wyrażenia myśli poetyckiej i tworzenia wizualnego obrazu (zarówno analogowego, jak i cyfrowego). Są to zatem z samego założenia pojęcia szersze niż miało to miejsce w przypadku Balcerzanowskich „wizualizmów”.

Zakres słowa „foto-grafem” nie zamyka się we wprost wyrażonych odwołaniach (w tym noszących cechy ekfrastyczności, szczególnie wyraźne w przypadku tekstów nawiązujących do tego medium już w tytułach) czy stosowaniu specyficznej metaforyki związanej z fotografią (odnoszącej się chociażby do sposobu kadrowania obrazu czy do gry między obecnością a nieobecnością fotografowanej postaci). Foto-grafemy można odnaleźć na wszystkich płaszczyznach tekstu (by nie powiedzieć: we wszystkich Ingardenowskich warstwach dzieła) - również w tych związanych z jego kształtem formalnym. Mogą one akcentować pojedyncze cechy fotografii bądź całe ich wiązki, również łącząc pojęcia - wydawałoby się - wobec siebie przeciwstawne. Nie wszystkie foto-grafemy są jednak tak samo czytelne. Niektóre z nich wydają się oczywiste już w pobieżnej lekturze tekstu - jak choćby te stanowiące bezpośrednie nawiązania do konkretnych zdjęć. Inne uwidaczniają się dopiero w akcie interpretacji, będąc w pewien sposób zależne od pozostałych, „silniejszych”. Relację tę szczególnie wyraźnie widać w warstwie formalnej utworu. Na przykład zastosowanie przerzutni samo w sobie trudno jest uznać za foto-grafem. W pewnych przypadkach jednak, gdy ten środek stylistyczny współistnieje z innymi, ewidentnymi foto-grafemami, również on nabiera takiego charakteru. Stąd też posługuję się pojęciem „podstawowego foto-grafemu”, który niejako ukierunkowuje całą interpretacją, odpowiednio „oświetlając” tekst. Poszczególne foto-grafemy wchodzą ze sobą w relacje, tworząc sieć zależności, składających się na foto-grafemiczność tekstu.

W przypadku wiersza Różyckiego podstawowy foto-grafem pojawia się w połowie drugiej strofy. Jest nim wprowadzenie w przestrzeń tekstu zdjęć, które mają stanowić element poświadczający osobistą walkę ze światem. Co istotne, Różycki nie definiuje zawartego na nich obrazu: w tekście próżno szukać szczegółowych informacji dotyczących sposobu kompozycji kadru czy tożsamości wszystkich osób w nim pomieszczonych ${ }^{17}$. Brak jednoznacznie wizualnego odniesienia do prezentowanej fotografii każe (zgodnie z wyrażoną wprost deklaracją) widzieć w niej przede wszystkim dokument - nie przedmiot podlegający ocenie w kategoriach estetycznych. Obraz ten - choć nie ulega bezpośredniemu opisowi - to jedyny zapis, mogący zaświadczać o przeszłości. Taki sposób tekstowego ukazania zdjęć, w którym wizualna forma obrazu zostaje niejako wzięta w nawias, paradoksalnie, zbliża to medium do językowych form wyrażania. Jak podkreślał Jacques Derrida:

\footnotetext{
${ }^{15}$ Catherine Malabou, Plastyczność u zmierzchu pisma: dialektyka, destrukcja, dekonstrukcja, tłum. Piotr Skalski (Warszawa: Wydawnictwo Naukowe PWN, 2018), 109.

${ }^{16}$ Por. tamże, s. 25.

${ }^{17}$ Dopiero w trzeciej strofie foto-grafem, jakim jest określenie „fotografie”, zostaje dookreślony poprzez okolicznik „z wesela”, który - choć również nie dostarcza tego typu informacji - pozwala wpisać zdjęcia w pewną konwencję.
} 
„Pierwsze pismo jest [...] namalowanym obrazem. [...] Jedno i drugie są najpierw pomieszane: zamknięty i niemy system, do którego mowa nie miała prawa wstępu i który oderwany był od wszelkiego osaczenia symbolicznego”18. Równocześnie, pewne „unieważnienie” wizualności obrazu, jakiego dokonuje tu Tomasz Różycki, uwypukla schematyczność zdjęć pamiątkowych (tak silną, że - jak zdaje się mówić autor - nie ma potrzeby ich szczegółowej literackiej charakterystyki).

Możliwość rozpoznania na zdjęciach samego siebie przydaje fotograficznemu zapisowi walor silnie tożsamościowy, niemal inskrypcyjny. Owa tożsamość w wypadku tego medium sprowadzona zostaje do rozpoznania twarzy. Jak pisał w Antropologii obrazu Hans Belting: „Analogia ciała i obrazu, spotęgowana w fotografii aż do indeksu ciała (Ch.S. Pierce) opierała się nie tylko na ufności w realność ciała, ale także na wierze, że realne ciało może reprezentować człowieka, którego ucieleśnia"19. Stąd też pojawiające się w wierszu Różyckiego stwierdzenie „jak to wynika ze zdjęć” każe widzieć fotografię przede wszystkim jako jeden z najsilniejszych możliwych sposobów potwierdzenia przeszłości (plasując się zresztą w nieco opozycyjnej pozycji wobec ludzkiej pamięci, niemal z defincji zawodnej i subiektywnej), a zarazem czyni ze zdjęć czytelne znaki ludzkiej obecności, które - by posłużyć się sformułowaniem Anny Łebkowskiej - „w swym unieruchomieniu, w swej funkcji wskazują to jest i tak było - odsłaniają ślad tego, co całkowicie poza możliwością uchwycenia"20.

W kontekście fotograficznego medium interesująca jest także sama metafora walki ze światem zwnętrznym. Jej dramatyzm podkreślony zostaje nie tylko poprzez wykorzystywanie słownictwa wojskowego (np. w sformułowaniu „desanty dmuchawców”), ale i sposób operowania opozycją statyki i dynamiki - tak silnie zakorzenioną w fotograficznym widzeniu świata. O ile wizja kreślona w pierwszej strofie (mimo pewnych zastrzeżeńn ${ }^{21}$ ) naznaczona jest ruchem przypisanym do sfery natury, o tyle pojawienie się w tekście fotografii zdaje się zatrzymywać ten obraz, zmieniając charakter tekstu z wraźnie deskryptywnego w kierunku niemal filozoficznej refleksji ${ }^{22}$ (podkreślonej nagromadzeniem pytań retorycznych). Xavier Farré, omawiając między innymi wiersz Zapach z tomiku Litery tego autora, podkreślał:

U Różyckiego oprócz zamrożenia obrazu, co stanowiłoby rodzaj ekphrasis, słowo wprawia w ruch ślepe pole i zaczyna żyć poza kadrem. Tam jest refleksja nad językiem, tam łączy się przeszłość poety i jego bliskich, tam jest cały świat poetycki, tam znajduje się droga do samookreślenia pośród tego, co widzalne i niewidzialne, pośród tego, co nazwane i tego, co teoretycznienie da się nazwać ${ }^{23}$.

\footnotetext{
${ }^{18}$ Derrida, O gramatologii, 362.

${ }^{19}$ Hans Belting, Antropologia obrazu. Szkice do nauki o obrazie, tłum. Mariusz Bryl (Kraków: Tow. Autorów i Wydawców Prac Naukowych Universitas, 2007), 135.

${ }^{20}$ Anna Łebkowska, „Fotografia jako empatyczna mediacja”, w Intersemiotyczność: literatura wobec innych sztuk (i odwrotnie), red. Stanisław Balbus, Andrzej Hejmej, i Jakub Niedźwiedź (Kraków: Towarzystwo Autorów i Wydawców Prac Naukowych „Universitas”, 2004), 126, http://books.google.com/books?id=EYAZAQAAIAAJ.

${ }^{21}$ Po stronie statyki lokowałby się również pierwszy wers utworu. Pytanie otwierające tekst („Kiedy dla nie zatańczysz?") zdaje się próbą uruchomienia świata pogrążonego w stagnacji. Podobnie należałoby czytać sformułowanie „Skończyło się lato" czy - znajdującą się już w drugiej strofie konstatację „dzieci nam urosły” stanowiące wyraz świadomości pewnego przesilenia, tożsamego z wkroczeniem (by podtrzyma retorykę Różyckiego) w jesień życia.

${ }^{22}$ Linia tego podziału w oczywisty sposób wpisuje się w cechy gatunkowe sonetu.

${ }^{23}$ Xavier Farré, „Kilka kadrów z wierszy Tomasza Różyckiego”, w Obroty liter: Szkice o twórczości Tomasza Różyckiego, red. Anna Czabanowska-Wróbel i Magdalena Rabizo-Birek (Kraków: Towarzystwo Autorów i Wydawców Prac Naukowych UNIVERSITAS, 2019), 115.
} 
Wyraźnie fotograficzna metafora, jaką jest pojęcie kadru (wykorzystywane zresztą przez Xaviera Farré również w tytule przytaczanego artykułu), pozwala podkreślić literacką grę między tym, co dostępne bezpośrednio, i tym, co skrywa się w interpretacyjnym geście. W podobny sposób w Lesie tropikalnym wykorzystywana zostaje opozycyjność ruchu i zatrzymania. Jak pisał Hans Finsler, „Fotografia to bezruch. Przerywa strumień życia”24. Doświadczenie owego „przerwania strumienia” zdaje się w tym utworze wyraźnie zakodowane. Taką kompozycję tekstu również można uznać za foto-grafem.

Przeciwstawienie ruchu i zatrzymania silnie wiąże się z rejestrowaniem upływu czasu - a co za tym idzie, przemijania. W problematykę tę włącza się opisywana przez Różyckiego wojna, przybierająca formę codziennej walki z czasem (w której - jak pisała Wisława Szymborska - „śmierć/ zawsze o tę chwilę przybywa spóźniona" ${ }^{25}$ ). W Lesie tropikalnym potyczka ta ma wymiar nie tylko egzystencjalny, ale i pokoleniowy. Choć wskazywany w tekście podział na dwie „strony” konfliktu wydaje się wraźny, to kryje się w nim ewidentny paradoks: „Wojnę ze światem/prowadziliśmy znowu [...] będąc po stronie świata". Zmianą dzielącą obydwa sposoby widzenia rzeczywistości byłby upływający czas, rejestrowany na fotografii - każący plasować się to po stronie młodych buntowników, to znowu wyznaczać zasady młodszemu pokoleniu. Bezpowrotna utrata młodości jest zresztą jednym z głównych tematów podejmowanych w tomiku Kolonie. „Zakopaliśmy nasze dzieciństwo/to już kwestia religii"26 - pisał w Przylądku Horn z tego właśnie zbioru Tomasz Różycki. Tytuł tomu odnosi się wszakże nie tylko do odległych krain czy procesu zdobywania kolejnych terytoriów, ale również podróży odbywających się w skali mikro, przynależnych do czasu dzieciństwa ${ }^{27}$. Ich świadectwem mogą być właśnie zdjęcia, pojawiające się w Lesie tropikalnym.

Roland Barthes w słynnym Świetle obrazu pisał: „Każdy akt lektury zdjęcia, a mamy ich miliardy codziennie na świecie, każdy akt uchwycenia i odczytania zdjęcia to bezpośredni i stłumiony kontakt z tym, czego już nie ma, czyli ze śmiercią" ${ }^{\text {"28 }}$. Problem przemijania Różycki wyraża również excplicite, pytając: „Czy dotyka/cię czas?”. Zdanie to można odczytywać nie tylko jako sposób podniesienia egzystencjalnego zagadnienienia, ale i foto-grafem oparty na odniesieniu do doświadczenia obcowania ${ }^{29} \mathrm{z}$ fotograficzną odbitką. Nieco oksymoroniczne wyrażenie „dotyk czasu” byłoby tożsame $z$ dotykiem osoby, oglądającej po latach swoje dawne zdjęcia ${ }^{30}$. Proces ten - tak głęboko zanurzony w somatycznym doświadczeniu - należałoby uznać za analogiczny do opisywanego przez Barthes’a krzyżującego się spojrzenia osoby patrzącej i postaci zarejestrowanej na zdjęciu.

Jednocześnie, foto-grafem ten wprowadza w tekst aspekt materialności fotograficznego obrazu - przypisywanej papierowej odbitce, lecz redukowalnej w przypadku cyfrowych technik reprodukcji. Marcela Kościańczuk w tekście Fotografia. Forma życia jako żałoby następująco inter-

\footnotetext{
${ }^{24}$ Hans Finsler, Das Bild der Photographie (Zurich: Conzett \& Huber, 1964), 2-54.

${ }^{25}$ Wisława Szymborska, „O śmierci bez przesady”, w Widok z ziarnkiem piasku: 102 wiersze (Kraków: Wydawn. a5, 2002), 107-8.

${ }^{26}$ Tomasz Różycki, „Przylądek Horn”, w Kolonie (Kraków: Wydawnictwo Znak, 2007), 12.

${ }^{27} \mathrm{Na}$ taką interpretację nakierowują chociażby utwory Rajska plaża, Węgorze elektryczne, Przylądek Horn czy wiele innych tekstów z tego tomiku. Por. również: Drzęźla, „O problemach tłumaczenia”.

${ }^{28}$ Roland Barthes, Światło obrazu: uwagi o fotografii, tłum. Jacek Trznadel (Warszawa: Wydawnictwo Aletheia, 2008$), 83$.

${ }^{29} \mathrm{~W}$ którym to sformułowaniu immanentnie kryje się element „obcości” tak wyraźnie akcentowanej przez Różyckiego.

${ }^{30}$ „Dotykam twojego zdjęcia. Przykładam je do czoła jak jasnowidz / tropiący ciała zaginionych” - pisał w tekście sięgającym podobnego doświadczenia Mariusz Więcek. Mariusz Więcek, „Robię Ci zoom i zachwycam się”, w Equilibrium (Sopot: Towarzystwo Przyjaciół Sopotu, 2009), 46.
} 
pretowała Barthes’owskie rozumienie silnej relacji łączącej fizyczność zdjęcia z somatycznością ludzkiego bytu, a zarazem doświadczeniem śmierci:

Forma, a zatem ciało czy zdjęcie, wskazuje, oznacza własną ułomność, kruchość, niedoskonałość. Proklamuje swoją pustkę, wieszcząc nieustannie przegraną wobec realizacji żywotności podmiotu. Zarazem jednak fotografia zapowiada jego śmierć, staje się zwiastunem ostatecznego, może w ten sposób nieco paradoksalnie dodając życiowej energii. Odbiorca zbuntowany czy też przeciwnie akceptujący nieuchronny koniec zapowiadany w zastygłych zmianach ciała czy martwocie fotografii ma szansę na dowartościowanie chwili zmiany wyrażającej dynamikę żywotności i rozpoznawalnej jedynie w konfrontacji ze stałością przedmiotu ${ }^{31}$.

Podoby walor zdaje się mieć dokonywane przez Różyckiego wyraźnie foto-grafemiczne zestawienie unieruchomienia obrazu zarejestrowanego na zdjęciu z dynamiką świata przyrody.

Wymiar mortaly fotografii spotęgowany jest także poprzez zmiany zachodzące na jej powierzchni: „Ze zdjęcia na zdjęcie, czy przypadkiem/nie znika jakiś drobny szczegół? I czy w końcu/tylko już tło zostanie?". Foto-grafemiczny zapis procesu blaknięcia obrazu, to nie tylko odwzorowanie technicznego problemu związanego z utratą jego szczegółów, ale i poręczna metafora działania ludzkiej pamięci - w której poszczególne twarze czy zdarzenia ulegają stopniowemu zanikowi. „Pismo” fotografii okazuje się zawodne, a znaki, z których zbudowany jest obraz, ulegają zatarciu. Derridiański ślad ludzkiej obecności staje się tylko nieznacznie bardziej trwały niż ona sama. Utrata zdjęcia jest tym boleśniejsza, że stanowi ono jedyny przedmiot, mogący poświadczyć o zarejestrowanych nań wydarzeniach.

W przypadku wiersza Las tropikany proces blaknięcia wykracza jednak poza obszar utrwalony w ramach jednego kadru. Różycki w wyraźny sposób pokazuje tu wszakże ciąg zdjęć. Ich wykonanie jest rozdzielone pewnym dystansem czasowym. Między poszczególnymi ujęciami wizerunek fotografowanej osoby „przenosi się”, ulegając coraz silniejszym przekształceniom, wynikającym z nieuchronnych procesów przemijania. Kolejne zdjęcia, niczym na filmie poklatkowym, dokumentują nie tylko śluby czy pogrzeby, ale przede wszystkim starzenie się ludzkiej twarzy, zmiany zachodzące w jej obrębie (współistniejące z tymi, dokonującymi się na powierzchni fotografii). Proces „przenoszenia” obrazu z jednego zdjęcia na drugie - niosący poniekąd również znamiona niemal kserograficznej replikacji - powoduje systematyczną utratę detali i niuansów, rozmywających się podczas poddawania ich kolejnym próbom zapisu. „I czy w końcu/tylko już tło zostanie?” - pyta Różycki. Puste zdjęcie, przedstawiające jedynie tło ${ }^{32}$ staje się najbardziej wymownym świadectwem ludzkiego przemijania.

„Drobny szczegół”, o który w cytowanej frazie pyta Różycki - ulegający stopniowemu rozmyciu na kolejnych odbitkach - byłby naważniejszym elementem fotograficznego zapisu. To wszakże jedyny znak, na który autor zwraca uwagę wprost. Mimo to, odnosi się on do cech w tekście nieokreślonych, funkcjonujących w przestrzeni Barthes'owskiego „trzeciego sensu”. Znak ten - wymykający się pierwotnemu kontekstowi, nakłuwający niczym punctum, zawierałby w sobie sedno ludzkiej tożsamości.

\footnotetext{
${ }^{31}$ Marcela Kościańczuk, „Fotografia. Forma życia jako żałoby”, w Imperium Rolanda Barthes’a, red. Anna Grzegorczyk i in. (Poznań: Wydawnictwo Naukowe Uniwersytetu im. Adama Mickiewicza, 2016), 266.

${ }^{32}$ Foto-grafem, jakim jest puste tło, w wyraźny sposób nawiązuje do wielu projektów artystycznych w podobny sposób ukazujących problem ludzkiego przemijania - np. serii zdjęć wykonywanych latami przez Kena Griffithsa, pokazujących tę samą parę na tle domu.
} 


\begin{abstract}
„Aby zbliżyć się do poznania kwintesencji fotografii, musimy uznać wartość fotograficzną za pojęcie niejasne, tej grafii nie realizuje bowiem swobodna ludzka ręka" ${ }^{33}$ - pisał w Nadmiarze widzialnego Edouard Pontremoli. W mechanicznym procesie wytwarzania obrazu „ręka” ludzka (którą trudno w tym przypadku nazwać „swobodną”) rzeczywiście zdaje się pełnić funkcję jedynie pomocniczą ${ }^{34}$. Nie oznacza to jednak, że sposób powstawania fotograficznej odbitki całkowicie podlega bezosobowemu działaniu techniki. Zdjęcia, będące podstawowym foto-grafemem trzeciej strofy utworu (zawartym we frazie „robione pod słońce/fotografie $z$ wesela”), są wyraźnie niedoskonałe - nie tylko ze względu na stopniowy zanik obrazu, ale również dlatego, że powstają na skutek działania człowieka. Szkolny błąd, jakim jest rejestrowanie obrazu pod światło, powoduje jego częściową utratę. Część znaków, które powinny zawierać się w ramach kadru, na zawsze pozostaje nieczytelna.
\end{abstract}

Fotograficzny zapis pojawający się w wierszu Różyckiego zdaje się zatem naznaczony pustką na wielu płaszczyznach: czy to ze względu na prześwietlenie materiału światoczułego (do którego doszło już w momencie rejestracji obrazu), czy to ze względu na ulotność fotograficznych odbitek, czy to wreszcie - zanikanie postaci na nich rejestrowanych. Fotografia zdaje się napiętnowana nieobecnością - niczym w innym wierszu z tomiku Kolonie tego autora, w którym czytamy: „Stare filmy i zdjęcia, pełna ich jest pustka,/i szafa i szuflada” ${ }^{35}$. Ta gra obecności i braku, immanentnie wpisana w pojęcie fotografii, zyskuje swój odpowiednik w ostatnich wersach utworu:
[...] Poprawiny były
i jutro będą znowu, chociaż puste wszystkie
butelki ze złym winem i na dnie kieliszka
zawsze coś pozostaje, jakieś fusy, miłość

Puste butelki po alkoholu okazują się taką samą pamiątką po minionych wydarzeniach, jak niedoskonałe zdjęcia.

W słynnej książce O fotografii Susan Sontag pisała:

Poezja zajmuje się konkretnym, autonomicznym językiem. Analogicznie fotografia bada czyste widzenie światła. Oba podejścia zakładają nieciągłość, niedoskonałość formy i arbitralną jedność twórczych decyzji. Zarówno poeci, jak fotografowie wyrywają przedmioty z kontekstu (patrzą na nie pod innym kątem), stosują śmiałe porównania i subiektywne kryteria własnego widzenia świata ${ }^{36}$.

Podobnie należałoby odczytywać sposób budowania literackich obrazów w wierszu Różyckiego. Przywoływane w ostatniej strofie przedmioty wyrywane są z kontekstu, niczym w fotogra-

\footnotetext{
${ }^{33}$ Edouard Pontremoli, Nadmiar widzialnego fenomenologiczna interpretacja fotogeniczności, tłum. Marian Leon Kalinowski (Gdańsk: Wydawn. Słowo, Obraz Terytoria, 2006), 9.

${ }^{34}$ Ludzka dłoń, poprzez wyzwolenie migawki, uruchamia szereg fizycznych, chemicznych oraz informatycznych (w przypadku fotografii cyfrowej) procesów. W dużym uproszczeniu, w przypadku zautomatyzowanej kreacji, specyfika poszczególnych ruchów ręki nie ma większego wpływu na wygląd powstającego obrazu (choć niewprawna ręka może „zepsuć” zdjęcie, na przykład poruszając aparatem). Taka metoda tworzenia wydaje się maksymalnie daleka od rysunku czy malarstwa, w których każdy gest ma swoje bezpośrednie odzwierciedlenie w powstającym obrazie (uwględnić tu należy nie tylko kierunek ruchu, ale i np. sposób nacisku czy kąt, pod jakim trzymane jest narzędzie).

${ }^{35}$ Tomasz Różycki, „Ziemia ognista”, w Kolonie (Kraków: Wydawnictwo Znak, 2007), 46.

${ }^{36}$ Susan Sontag, O fotografii, tłum. Sławomir Magala (Kraków: Wydawnictwo Karakter, 2009), 92.
} 
ficznym procesie kadrowania, nakierowującym odbiorcę na (wydawałoby się nic nieznaczące) detale. W podkreślane przez Sontag „subiektywne kryteria widzenia świata” wpisywałoby się również wykorzystanie przerzutni - analogicznych wobec „ostrego cięcia” fotograficznego kadru. Taka metoda konstrukcji wiersza (choć w oczywisty sposób spotykana również w tekstach nieodnoszących się do fotografii) w tym kontekście również może być uznana za foto-grafem rozumiany jako punkt styku między dwoma przyległymi mediami. Podobnie należałoby interpretować pewnego rodzaju migawkowość obrazów pojawiających się w pierwszej strofie tekstu.

Przedmioty, na które - niczym za pomocą fotograficznego zooma - wskazuje Różycki mają za zadanie udowodnić, że wpisana w zakończenie utworu utrata sensu nie może być całkowita. „Zawsze coś pozostaje” - deklaruje poeta. W Nie bez reszty Tadeusz Sławek pytał: „Czym jest «reszta»? [...] powiedzmy, czym «reszta» nie jest. Sugestia pierwsza: nie jest tym, co odsuwamy od siebie jako nieważne, co pozostaje poza obrębem naszego zainteresowania"37. Rudymentarność „reszty” wyraźnie (ale i nieco paradoksalnie) wiąże się - jak pokreślał Sławek - z metaforą wysypiska, na którym lądują przedmioty, znajdujące się w sytuacji „przejścia, tranzytu”38. U Różyckiego to właśnie fusy, śmieci, strzępy emocji, dalekie echa wydarzeń stają się „resztą” - dającą możliwość wspominania. Włączenie na równych prawach w szereg tego wyliczenia miłości w ironiczny sposób pokazuje wagę tego uczucia.

W tym kontekście warto oddać jeszcze raz głos Tadeuszowi Sławkowi, który książkę Nie bez reszty kończył następująco:

Powraca więc nieuchronnie pamięć, ale nie jest to już pamięć, którą zawiaduję. Nie ma charakteru archiwum, z którego dowolnie i na życzenie wyciągam stosowny dokument wspomnienia. Muszę uznać, że to nie jest pamięć moja, a stąd już tylko krok do przyznania, że ma ona własne mechanizmy i pragnienia, które nie podporządkowują się moim życzeniom ${ }^{39}$.

Ta pamięć, niejako autonomiczna, wyzwolona spod ludzkiej woli, niezwykle często uruchamia się właśnie w zetknięciu z dawnymi zdjęciami - „nakłuwającymi” Barthes’owskim punctum. Bardzo podobny mechanizm sprawia, że - jak pisze Różycki - „poprawiny były/i jutro będą znowu”, a czas, odmierzany rytmem kolejnych analogicznych wydarzeń, wydaje się zataczać koło. Utwory poetyckie, wpisujące się w pojęcie foto-grafemiczności to w dużej mierze tekstowy zapis tego typu doświadczeń.

Foto-grafemiczność należałoby uznać za zespół cech funkcjonujących na bardzo różnych poziomach tekstu. Wprowadzenie w przestrzeń literatury fotograficznego medium nie zawsze ma wszakże formę bezpośrednich odwołań. W tekście Las tropikalny prócz nich pojawia się także wiele innych foto-grafemów, które pozwalają wydobyć cechy tego medium i przenieść je na płaszczyznę poetycką - poczynając od wpisanej weń metafory „dotyku czasu”, na konstrukcji utworu, eksponującej kwestię ruchu i znieruchomienia czy sposób działania fotograficznego kadru, kończąc. Bez ich wskazania trudno w pełni zrekonstruować relacje łączące literaturę $\mathrm{z}$ fotografią.

\footnotetext{
${ }^{37}$ Tadeusz Sławek, Nie bez reszty: o potrzebie niekompletności (Mikołów: Instytut Mikołowski, 2018), 5.

${ }^{38}$ Tamże, s. 200

${ }^{39}$ Tamże, s. 202.
} 


\section{Bibliografia}

Balcerzan, Edward. „Widzialne i niewidzialne w sztuce słowa”. W Kulturowe wizualizacje doświadczenia, zredagowane przez Włodzimierz Bolecki i Adam Dziadek. Warszawa: Instytut badań literackich: Fundacja „Centrum międzynarodowych badań polonistycznych, 2010.

Barthes, Roland. Światło obrazu: uwagi o fotografii. Przetłumaczone przez Jacek Trznadel. Warszawa: Wydawnictwo Aletheia, 2008.

Belting, Hans. Antropologia obrazu. Szkice do nauki o obrazie. Przetłumaczone przez Mariusz Bryl. Kraków: Tow. Autorów i Wydawców Prac Naukowych Universitas, 2007.

Derrida, Jacques. O gramatologii. Przetłumaczone przez Bogdan Banasiak. Łódź: Wydawnictwo Officyna, 2011.

Drzęźla, Magdalena. „O problemach tłumaczenia”. Kwartalnik Opolski : organ Opolskiego Towarzystwa Przyjaciół Nauk., nr 4 (2010): 147-62.

Dziadek, Adam. Obrazy i wiersze: z zagadnień interferencji sztuk $w$ polskiej poezji współczesnej. Katowice: Wyd. Uniwersytetu Śląskiego, 2011.

Edelman, Lee. „Homographesis”. W Formy męskości 3, zredagowane przez Adam Dziadek i Filip Mazurkiewicz, przetłumaczone przez Dawid Matuszek, Instytut Badań Literackich PAN. Warszawa, 2018.

Farré, Xavier. „Kilka kadrów z wierszy Tomasza Różyckiego". W Obroty liter: Szkice o twórczości Tomasza Różyckiego, zredagowane przez Anna Czabanowska-Wróbel i Magdalena Rabizo-Birek. Kraków: Towarzystwo Autorów i Wydawców Prac Naukowych UNIVERSITAS, 2019.

Finsler, Hans. Das Bild der Photographie. Zurich: Conzett \& Huber, 1964. 
Kościańczuk, Marcela. „Fotografia. Forma życia jako żałoby”. W Imperium Rolanda Barthes'a, zredagowane przez Anna Grzegorczyk, Agnieszka Kaczmarek, Katarzyna Machtyl, i Bogusław Żyłko. Poznań: Wydawnictwo Naukowe Uniwersytetu im. Adama Mickiewicza, 2016.

Logan, Marie-Rose. „Graphesis...” Yale French Studies Yale French Studies 52, nr 4 (1975).

Łebkowska, Anna. „Fotografia jako empatyczna mediacja”. W Intersemiotyczność: literatura wobec innych sztuk (i odwrotnie), zredagowane przez Stanisław Balbus, Andrzej Hejmej, i Jakub Niedźwiedź. Kraków: Towarzystwo Autorów i Wydawców Prac Naukowych „Universitas”, 2004. http://books.google.com/ books?id=EYAZAQAAIAAJ.

Malabou, Catherine. Plastyczność u zmierzchu pisma: dialektyka, destrukcja, dekonstrukcja. Przetłumaczone przez Piotr Skalski. Warszawa: Wydawnictwo Naukowe PWN, 2018.

Piotrowska-Grot, Magdalena. „Po kolei wszystkie warianty". W Obroty liter: Szkice o twórczości Tomasza Różyckiego, zredagowane przez Anna Czabanowska-Wróbel i Magdalena Rabizo-Birek. Kraków: Towarzystwo Autorów i Wydawców Prac Naukowych UNIVERSITAS, 2019.

Pontremoli, Edouard. Nadmiar widzialnego fenomenologiczna interpretacja fotogeniczności. Przetłumaczone przez Marian Leon Kalinowski. Gdańsk: Wydawn. Słowo, Obraz Terytoria, 2006.

Rabizo-Birek, Magdalena. „Poezja bliska”. W Obroty liter: Szkice o twórczości Tomasza Różyckiego, zredagowane przez Anna Czabanowska-Wróbel i Magdalena Rabizo-Birek. Kraków: Towarzystwo Autorów i Wydawców Prac Naukowych UNIVERSITAS, 2019.
Rosenthal, Mira. „Teraźniejszość jako niekończąca się chwila wahania". W Obroty liter: Szkice o twórczości Tomasza Różyckiego, zredagowane przez Anna Czabanowska-Wróbel i Magdalena Rabizo-Birek, przetłumaczone przez Tomasz Bilczewski i Anna Kowalcze-Pawlik. Kraków: Towarzystwo Autorów i Wydawców Prac Naukowych UNIVERSITAS, 2019.

Różycki, Tomasz. „Las tropikalny”. W Kolonie. Kraków: Wydawnictwo Znak, 2007.

——_. „Przylądek Horn”. W Kolonie. Kraków: Wydawnictwo Znak, 2007.

-_—. „Ziemia ognista”. W Kolonie. Kraków: Wydawnictwo Znak, 2007.

Sławek, Tadeusz. Nie bez reszty: o potrzebie niekompletności. Mikołów: Instytut Mikołowski, 2018.

Sontag, Susan. O fotografii. Przetłumaczone przez Sławomir Magala. Kraków: Wydawnictwo Karakter, 2009.

Szymborska, Wisława. „O śmierci bez przesady”. W Widok z ziarnkiem piasku: 102 wiersze. Kraków: Wydawn. a5, 2002.

Tabaszewska, Justyna. „Powtórzenia i ponowienia,/. Tomasz Różycki a kwestia oryginalności”. W Obroty liter: Szkice o twórczości Tomasza Różyckiego, zredagowane przez Anna Czabanowska-Wróbel i Magdalena Rabizo-Birek. Kraków: Towarzystwo Autorów i Wydawców Prac Naukowych UNIVERSITAS, 2019.

Więcek, Mariusz. „Robię Ci zoom i zachwycam się". W Equilibrium. Sopot: Towarzystwo Przyjaciół Sopotu, 2009. 


\section{SEOWA KLUCZOWE:}

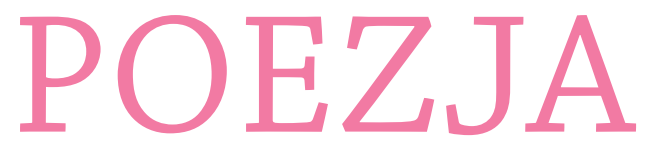

$$
\text { fotografia }
$$

\section{Abstrakt:}

Tekst stanowi analizę intertekstualnych relacji łączących literaturę $\mathrm{z}$ fotografią. W celu ich wydobycia autorka proponuje wykorzystanie pojęć "foto-grafemiczności" tekstu (rozumianej jako zespół cech wskazujących na pokrewieństwo tekstu i fotografii) oraz „foto-grafemu” (będącego ich jednostkową tekstową realizacją), inspirowanych Derridiańskimi kategoriami „gramatologicznymi”. Sposób ich funkcjonowania w tekście poetyckim zaprezentowany zostaje na przykładzie wiersza Las tropikalny Tomasza Różyckiego. 
literatura polska LITERATURA
XXI WIEKU

\section{NOTA O AUTORZE:}

Barbara Englender (ur. 1988) - doktorantka na Uniwersytecie Śląskim w zakresie literaturoznawstwa polskiego. Absolwentka filologii polskiej i kulturoznawstwa. Jej głównym obszarem zainteresowań są relacje między poezją najnowszą a fotografią. Autorka licznych artykułów naukowych w czasopismach (m.in. „Maska”, „Fragile”, „Radomskie Studia Filologiczne") oraz monografiach. 